\title{
Predictive utility of postoperative serum myoglobin in acute kidney injury after liver transplantation
}

\author{
Yu-Zhen Han", Jin Zhang", Rong-Yue Gao, Song Zhao, Yue Zheng, Qi Ding, Xin Xin, Kai Yu, \\ Li-Feng Huang, Wen-Xiong Li
}

Department of Surgical Intensive Care Unit, Beijing Chaoyang Hospital Affiliated to Capital Medical University, Beijing, China

Contributions: (I) Conception and design: YZ Han, J Zhang, LF Huang; (II) Administrative support: YZ Han, J Zhang; (III) Provision of study materials or patients: YZ Han, RY Gao, S Zhao, Y Zheng, Q Ding, X Xin, K Yu; (IV) Collection and assembly of data: YZ Han, RY Gao; (V) Data analysis and interpretation: YZ Han, LF Huang; (VI) Manuscript writing: All authors; (VII) Final approval of manuscript: All authors.

\#These authors contributed equally to this work.

Correspondence to: Wen-Xiong Li; Li-Feng Huang. Department of Surgical Intensive Care Unit, Beijing Chaoyang Hospital Affiliated to Capital Medical University, 8 Gongren Tiyuchang Nanlu, Chaoyang District, Beijing 100020, China. Email: lwx7115@sina.com; burnshlf@sina.com.

Background: Acute kidney injury (AKI) is a common and multifactorial complication after liver transplantation (LT). Myoglobin (Mb) which can be served as $\mathrm{O}_{2}$ storage and delivery depot is present in muscles and cardiac myocytes. Previous studies had shown the close relationship between Mb and AKI. But there is a lack of clinical studies for Mb with the risk of AKI due to LT. This study was performed to determine the association between the serum level of $\mathrm{Mb}$ and incidence of AKI in patients underwent LT.

Methods: The clinical data of 140 consecutive adult patients who underwent LT at our center from June 2018 to August 2020 were analyzed in this study. One hundred and fifteen patients met the inclusion criteria. The performances of postoperative laboratory variables (including serum $\mathrm{Mb}$ ) were evaluated. The outcomes after LT, including the duration of intensive care unit (ICU) stay, hospital stay and 28-day mortality, were also measured.

Results: We divided 115 patients into AKI group ( $n=44)$ and non-AKI group ( $n=71)$. Serum Mb on postoperative day 0 (POD0) was significantly higher in AKI group than those in non-AKI group $(\mathrm{P}<0.001)$. According to univariate and multivariable logistic regression analysis, the levels of serum albumin $(\mathrm{P}=0.024)$, alanine transaminase $(\mathrm{P}=0.007)$ and $\mathrm{Mb}(\mathrm{P}=0.006)$ on $\mathrm{POD} 0$ were independently associated with development of new AKI. The area under curve (AUC) of serum Mb after LT immediately had the best value for predicting AKI [AUC: 0.755, sensitivity: 63.6\%, specificity: 77.3\%, 95\% confidence interval (CI): 0.661-0.849], its cut-off value was $957 \mathrm{ng} / \mathrm{mL}$.

Conclusions: Postoperative serum Mb was an independent risk factor for new AKI and could increase the accuracy of predicting the occurrence of post-LT AKI.

Trial Registration: The study was registered in Chinese Clinical Trial Registry (registration number: ChiCTR2100044257).

Keywords: Myoglobin (Mb); acute kidney injury (AKI); liver transplantation (LT)

Submitted Aug 21, 2021. Accepted for publication Sep 15, 2021.

doi: $10.21037 /$ apm-21-2340

View this article at: https://dx.doi.org/10.21037/apm-21-2340 


\section{Introduction}

Liver transplantation (LT) which can significantly improve the quality of life and improve long-term results continues be the only available treatment for patients with end-stage liver disease such as liver cancer or acute and subacute liver failure (1). In the past decade, the survival rate of patients after LT has increased substantially, but the incidence of postoperative complications remains high due to drastic pathophysiological changes such as hemodynamic alterations and inflammation-related stress (2-4).

During LT, hemodynamic instability will occur when interrupt the portal vein, resulting in major organ hypoperfusion. Such as concomitant acute kidney injury (AKI), with high morbidity and mortality, is not uncommon after LT which related to poor prognosis (5-7). In addition, postoperative AKI, even when transient, has been associated with poor long-term graft and a reduced patient survival. And even in patients with normal preoperative renal function, $\mathrm{AKI}$ is frequent $(8,9)$. Therefore, it is important to identify the novel risk factors to prevent its occurrence. To date, many studies have tried to find the biomarkers to predict AKI, such as neutrophil gelatinase-associated lipocalin (NGAL), cystatin $\mathrm{C}$ and interleukin-18, and prevent the occurrence of it (10-12). Moreover, the treatments of AKI were still controversial, although serval strategies have been studied (13). Thus the early and rapidly diagnosis and therapy of AKI is a critical part of the management.

Patients after major operation are often hyper-myoglobin (hyper-Mb), due to intraoperative muscle damaged by physical or biochemical injury. So during LT, intraoperative trauma might be the cause of raised $M b$ (14). Mb, with small molecular, is a pigment protein which is freely filtered by the glomerulus, enters the tubule epithelial through endocytosis, and is widely found in muscle tissue (15). After muscle damage, $\mathrm{Mb}$ is rapidly released into the blood, and is immediately eliminated by the kidney. So an accumulation of large amount $\mathrm{Mb}$ in the distal renal tubule is responsible for AKI as a consequence. Instead of muscle injury, the elevated serum $\mathrm{Mb}$ level can also be observed in these following conditions: multi-organ failure, sever infection and major surgery (16). Furthermore, it has been shown that $\mathrm{Mb}$ itself is significantly related to poor outcome of diseases such as acute trauma, myocardial infarction, severe sepsis and so on $(17,18)$.

There are many independent risk factors for the occurrence of AKI after LT including early postoperative hypoalbuminemia, preoperative higher vitamin B12, intraoperative hypotension, postoperative severe infection, and peak $\log$ of aspartate aminotransferase (AST) at postoperative which have been indicated in previous studies (19-23). However, the correlation between the levels of serum $\mathrm{Mb}$ and the occurrence of AKI after LT is still no clear. Furthermore, if the patients who underwent LT and got AKI can be identified and intervened early, it will facilitate renal function recovery. The current study aimed to evaluate and validate the occurrences of AKI with serum levels of $\mathrm{Mb}$ in patients after LT. We also determined the clinical predictive value of $\mathrm{Mb}$ for $\mathrm{AKI}$ as a potential biomarker. We present the following article in accordance with the STARD reporting checklist (available at https:// dx.doi.org/10.21037/apm-21-2340).

\section{Methods}

\section{Study population}

This study prospectively collected the data from 140 consecutive adult patients (age $>18$ years) underwent orthotopic LT (OLTx) in surgical intensive care unit (ICU) of Beijing Chaoyang Hospital between June 2018 and August 2020 which collected by the electronic medical record system. All patients have given their informed consent prior to their inclusion in the study. Our liver allografts were from donation after cardiac death (DCD). Piggy back or veno-venous bypass were not used in all patients. The study conformed to the provisions of the Declaration of Helsinki (as revised in 2013). Our study was approved by the Institutional Review Board (Beijing Chaoyang Hospital Affiliated to Capital Medical University, approval number: 2021-55). Patients were excluded if they met any of the exclusion criteria: (I) preoperative AKI; (II) preoperative CKD; (III) expecting to die within 3 days after LT. At last, a total of 25 patients were excluded from analysis, the remaining 115 patients were analyzed.

\section{Clinical data}

According to the previous study, the data associated with postoperative AKI after LT were collected $(5,20,24,25)$. Baseline characteristics of patients were obtained including age, sex, body mass index (BMI), model for end-stage liver disease (MELD) score, Child-Pugh classification, aetiology for LT (tumor, viral disease, alcoholic or others), and history of hypertension, diabetes mellitus, coronary disease 
or infection, as well as use of diuretics and nephrotoxic drug including vancomycin, aminoglycosides, rifampicin, amphotericin B, immunosuppressants and chemotherapy, etc. Laboratory data included leukocyte, hemoglobin, platelets, albumin, AST and alanine aminotransferase (ALT), total bilirubin (TB), direct bilirubin (DB), indirect bilirubin (IB), ammonia, international normalized ratio (INR), prothrombin time (PT) and creatinine at preoperative. These data were collected from the latest preoperative data. Intraoperative data included duration of operation, intraoperative blood loss, transfusion volume of blood components, fluid balance, urine output, the maximum dose of norepinephrine, cold ischemic time (CIT) and warm ischemic time (WIT). The mean urine output was calculated by averaging the total collected volume during surgery. Furthermore, serum albumin, AST, ALT, TB, $\mathrm{DB}, \mathrm{IB}, \mathrm{PT}$, INR, prothrombin activity $(\mathrm{PA})$ and ammonia of patients were measured again on admission to ICU immediately [post-operative day 0 (POD0)]. The first test result which measured after surgery immediately of serum $\mathrm{Mb}$ and procalcitonin (PCT) were also obtained. Otherwise, mean arterial pressure (MAP), Sequential Organ Failure Assessment (SOFA) score and Acute Physiology Chronic Health Disease Classification System II (APACHE II) score were also collected after entering ICU immediately. All data can be extracted directly from the electronic medical record system.

\section{Outcomes and definitions}

Our primary outcome was the incidence of new AKI within 72 hours after operation. The secondary outcomes were 28-day mortality, the length of ICU and hospital stay, as well as the incidence of early allograft dysfunction (EAD) and primary allograft non-function (PNF). We defined AKI based on the maximal change in serum creatinine level within POD3, not urine output, according to the Kidney Disease: Improving Global Outcome (KDIGO) criteria (Table S1): an increase in serum creatinine by $\geq 26.5 \mu \mathrm{mol} / \mathrm{L}$ $(\geq 3 \mathrm{mg} / \mathrm{dL}$ ) within $48 \mathrm{~h}$; or an increase in serum creatinine to $\geq 1.5$ times baseline, which is known or presumed to have occurred within the first 3 days PODs. AKI was classified based on increase of serum creatinine as followed: stage 1 , 1.5-1.9; stage 2, 2-2.9; stage 3, $>3$ folds increase from the baseline respectively within the first 3 days $(26,27)$. Baseline creatinine was the most recent result before operation. However, if the baseline creatinine was not available, it will be estimated by formula as followed: serum creatinine $=\{75 /$ $\left[186 \times\left(\right.\right.$ age $\left.^{-0.203}\right) \times(0.742$ if female $) \times(1.21$ if black $\left.\left.)\right]\right\}^{-0.887}(27)$. We also recorded whether patients needed continuous renal replacement therapy (CRRT). CRRT was initiated if patients met at least one of the following conditions: severe acidosis $(\mathrm{pH}<7.15)$; severe hyperkalemia $\left(\mathrm{K}^{+}>6.5 \mathrm{mmol} / \mathrm{L}\right)$; severe pulmonary edema resistant to diuretics; oliguria $>72$ hours; serum urea $>40 \mathrm{mmol} / \mathrm{L}$ (28). The diagnosis of $\mathrm{EAD}$ was required to meet one or more the following terms: ALT level or AST level $>2,000 \mathrm{IU} / \mathrm{mL}$ within the first 7 PODs; bilirubin $10 \mathrm{mg} / \mathrm{dL}$ on POD7; INR 1.6 on POD7. PNF was defined as the requirement of retransplantation or leading to death within 7 PODs (29).

\section{Statistical analysis}

SPSS statistical software version 26.0 (IBM, Chicago, IL, USA), GraphPad Prism 8.3.0 (Graphpad Software Inc., San Diego, CA, USA) were used to perform all analysis in our study. Participants were categorized into AKI group and non-AKI group based on KDIGO criteria. This study compared the baseline characteristics between two groups using $t$-test, the $\chi^{2}$ test or Fisher's exact test and the Mann Whitney $\mathrm{U}$ test, as appropriate. Continuous variables were described as mean \pm standard deviations (SDs) or median [interquartile range (IQR)]. Categorical variables were described as absolute counts and percentages. The integrity was achieved using multiple imputations to account for missing data. The association between perioperative factors as well as laboratory data and AKI was analyzed with univariate and multivariate logistic regression. Those factors which is potentially significant $(\mathrm{P}<0.1)$ in univariate logistic analyses were entered into multivariate logistic analyses. We produced the receiver operating characteristic (ROC) curve to assess the level of $\mathrm{Mb}$ and the diagnostic prediction of AKI. The diagnostic performance was evaluated through the area under the ROC curve (AUC-ROC). And the sensitivity, specificity and their corresponding $95 \%$ confidence intervals (CIs) were recorded, as well as cut-off value for the best predict parameter. $\mathrm{P}$ values under 0.05 were considered statistically significant.

\section{Sample size}

According to previous study, the incidence of AKI after LT was $46.7 \%$. A sample of 110 was required at a significance level of $\alpha=0.05$, with a power of $85 \%$ and allow for $10 \%$ missing data. 
Table 1 Demographic data and clinical characteristics of patients

\begin{tabular}{|c|c|c|c|c|}
\hline Group & All $(n=115)$ & $A K I(n=44)$ & Non-AKI (n=71) & $P$ value \\
\hline Age (years) & $53[48,60]$ & $52[48,59]$ & $54[48,60]$ & 0.557 \\
\hline Male gender, n (\%) & $100(86.9)$ & $39(88.6)$ & $61(85.9)$ & 0.674 \\
\hline BMI $\left(\mathrm{kg} / \mathrm{m}^{2}\right)$ & $23.7[20.8,25.8]$ & $23.9[20.6,26.2]$ & $23.6[21.0,25.5]$ & 0.848 \\
\hline MELD-Na score & $13.3[8.0,15.5]$ & $14.5[8.0,18.0]$ & $12.5[8.5,14.1]$ & 0.345 \\
\hline \multicolumn{5}{|c|}{ Child-Pugh classification, n (\%) } \\
\hline Class A & $24(20.9)$ & $9(20.5)$ & $15(21.1)$ & 0.931 \\
\hline Class B or $\mathrm{C}$ & $91(79.1)$ & $35(79.5)$ & $56(78.9)$ & \\
\hline \multicolumn{5}{|c|}{ Etiology of liver disease, n (\%) } \\
\hline Alcohol-related & $7(6.1)$ & $2(4.5)$ & $5(7.0)$ & 0.586 \\
\hline Viral diseases & $38(33.0)$ & $15(34.1)$ & $23(32.4)$ & 0.851 \\
\hline Liver tumor & $52(45.2)$ & $20(45.5)$ & $32(45.1)$ & 0.868 \\
\hline Other liver diseases & $18(15.7)$ & $7(15.9)$ & $11(15.5)$ & 0.952 \\
\hline \multicolumn{5}{|l|}{ Comorbidity, n (\%) } \\
\hline Diabetes mellitus & $23(20.0)$ & $8(18.2)$ & $15(21.1)$ & 0.701 \\
\hline Hypertension & $22(19.1)$ & $8(18.2)$ & $14(19.7)$ & 0.839 \\
\hline
\end{tabular}

Nephrotoxic drug primarily include vancomycin, aminoglycosides, rifampicin, amphotericin B, immunosuppressants and chemotherapy. AKI, acute kidney injury; BMI, body mass index; MELD, model for end-stage liver disease.

\section{Results}

\section{Baseline characteristics}

The parameters between two groups were compared, as summarized in Table 1. One hundred and fifteen patients were screened in this study and they were largely male (86.9\%). According to the definition of AKI, there were 44 (38.3\%) patients with AKI as the AKI group and another $71(61.7 \%)$ patients without AKI as the non-AKI group (Figure 1). There was no significant difference in diuretics use, nephrotoxic drugs use and other baseline characteristics between two groups.

\section{Perioperative laboratory data}

A comparison of the preoperative, intraoperative and postoperative data was listed in Table 2. The duration of surgery was higher in patients with AKI than these without AKI $[9.69$ (7.86, 10.79) vs. 8.66 (7.43, 9.58), $\mathrm{P}=0.026]$. Moreover, the mean (IQR) of urine output at intraoperative were $155[92,191] \mathrm{mL} / \mathrm{h}$ for the patients with AKI and $219[150,270] \mathrm{mL} / \mathrm{h}$ for those without AKI $(\mathrm{P}<0.001)$. Maximum dose of norepinephrine was also lower in the non-AKI group than in the AKI group $(\mathrm{P}=0.030)$. We measured biochemical and coagulation indexes again when 


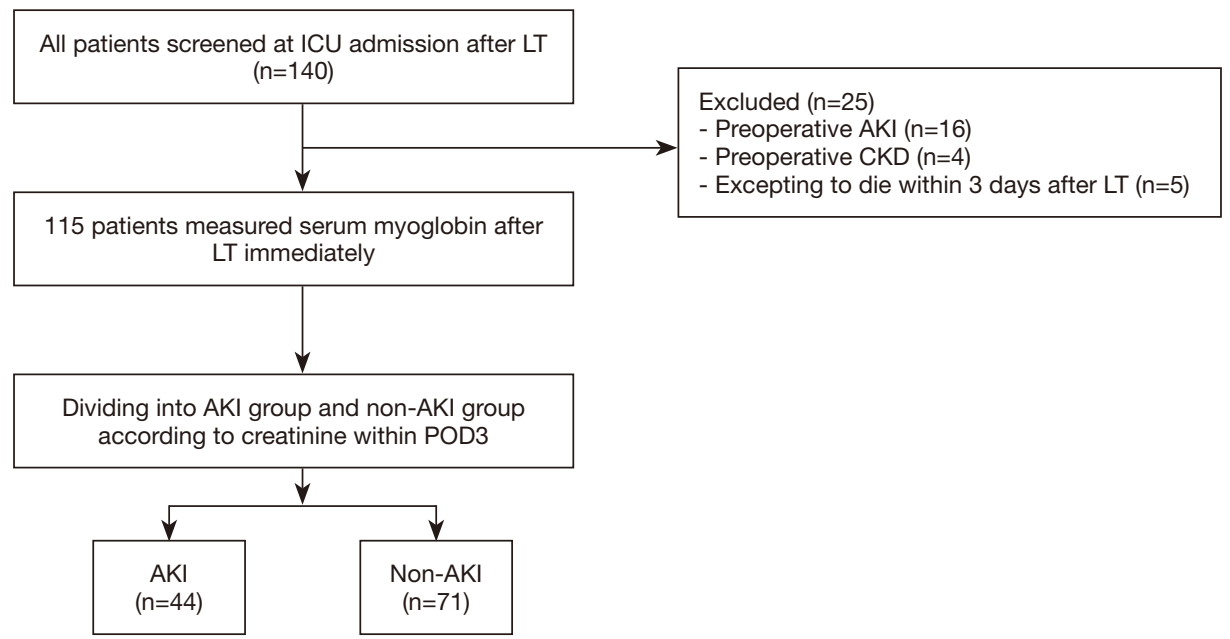

Figure 1 Study flow chart. ICU, intensive care unit; LT, liver transplantation; POD, post-operative day; AKI, acute kidney injury; CKD, chronic kidney disease.

Table 2 Preoperative laboratory parameters, intraoperative characteristics and outcomes of the study patients

\begin{tabular}{|c|c|c|c|c|}
\hline Group & All $(n=115)$ & AKI $(n=44)$ & Non-AKI $(n=71)$ & $P$ value \\
\hline WBC count $\left(10^{9} / \mathrm{L}\right)$ & $4.18[2.27,5.21]$ & $4.51[2.56,5.12]$ & $3.98[2.13,5.24]$ & 0.676 \\
\hline NLR (\%) & $4.48[1.75,5.10]$ & $4.94[1.75,4.87]$ & $4.23[1.73,4.42]$ & 0.581 \\
\hline Hemoglobin (g/L) & $110.4 \pm 28.0$ & $105.8 \pm 26.1$ & $113.0 \pm 29.3$ & 0.211 \\
\hline Albumin (g/L) & $34.8 \pm 6.9$ & $33.9 \pm 6.1$ & $35.5 \pm 7.4$ & 0.308 \\
\hline Serum creatinine $(\mu \mathrm{mol} / \mathrm{L})$ & $62.3 \pm 15.3$ & $60.3 \pm 17.9$ & $63.6 \pm 13.4$ & 0.074 \\
\hline Urea (mmol/L) & $5.71[4.03,6.30]$ & $5.78[4.40,6.06]$ & $5.67[3.94,6.73]$ & 0.437 \\
\hline Sodium (mmol/L) & $138.1[136.8,140.6]$ & $138.1[136.9,140.7]$ & $138.1[136.7,140.6]$ & 0.903 \\
\hline AST (U/L) & $55[27,54]$ & $47[29,55]$ & $58[26,52]$ & 0.448 \\
\hline ALT (U/L) & $36[20,43]$ & $29[20,37]$ & $41[20,45]$ & 0.225 \\
\hline PT (s) & $16.8[13.7,19.3]$ & $17.5[13.8,19.9]$ & $16.3[13.4,18.4]$ & 0.209 \\
\hline INR & $1.63[1.13,1.67]$ & $1.96[1.15,1.72]$ & $1.42[1.13,1.59]$ & 0.229 \\
\hline PA (\%) & $63.5[46.5,80.4]$ & $60.4[45.7,75.8]$ & $65.5[50.0,80.9]$ & 0.340 \\
\hline Ammonia ( $\mu \mathrm{mol} / \mathrm{L})$ & $83.3[52.5,119.5]$ & $81.9[51.0,119.0]$ & $84.1[56.0,108.5]$ & 0.928 \\
\hline \multicolumn{5}{|l|}{ Intraoperative data } \\
\hline Duration surgery (hours) & $9.07[7.67,10.11]$ & $9.69[7.86,10.79]$ & $8.66[7.43,9.58]$ & 0.026 \\
\hline
\end{tabular}

Table 2 (continued) 
Table 2 (continued)

\begin{tabular}{|c|c|c|c|c|}
\hline Group & All $(n=115)$ & AKI $(n=44)$ & Non-AKI $(n=71)$ & $P$ value \\
\hline Intraoperative urine output (mL/h) & $194[120,262]$ & $155[92,191]$ & $219[150,270]$ & $<0.001$ \\
\hline Fluid balance (L) & $4.09[2.93,4.91]$ & $4.58[3.49,5.25]$ & $3.76[2.80,4.75]$ & 0.036 \\
\hline Duration of IVC interruption (min) & $77[73,93]$ & $75[55,95]$ & $78[60,89]$ & 0.391 \\
\hline CIT (h) & $6.9[0.5,10]$ & $7.1[1,13]$ & $6.7[0.5,10]$ & 0.903 \\
\hline Warm ischemic time (min) & $29.6[10,30]$ & $31.3[10,50]$ & $27.5[10,50]$ & 0.325 \\
\hline \multicolumn{5}{|l|}{ Postoperative data ${ }^{\ddagger}$} \\
\hline $\mathrm{Mb}(\mathrm{ng} / \mathrm{mL})$ & $1,076[518,1,296]$ & $1,531[717,1,969]$ & $772[435,940]$ & $<0.001$ \\
\hline ALT (U/L) & $819[277,1,066]$ & $1186[332,2128]$ & $576[273,745]$ & 0.006 \\
\hline $\mathrm{TB}(\mu \mathrm{mol} / \mathrm{L})$ & $89.8[40.8,100.9]$ & $98.9[45.5,123.7]$ & $81.3[40.7,91.6]$ & 0.060 \\
\hline $\mathrm{DB}(\mu \mathrm{mol} / \mathrm{L})$ & $59.3[26.2,65.6]$ & $63.9[26.0,77.6]$ & $54.0[25.7,58.8]$ & 0.281 \\
\hline PT (s) & $24.1[19.4,27.9]$ & $27.6[20.9,33.6]$ & $22.1[19.0,25.3]$ & $<0.001$ \\
\hline INR & $2.18[1.69,2.55]$ & $2.47[1.87,2.93]$ & $1.98[1.65,2.21]$ & 0.001 \\
\hline PA (\%) & $38.2[28.9,45.8]$ & $32.5[23.6,40.5]$ & $41.3[33.7,49.4]$ & 0.001 \\
\hline Ammonia ( $\mu \mathrm{mol} / \mathrm{L})$ & $74.7[45.0,89.5]$ & $95.8[48.0,125.0]$ & $61.0[41.0,78.0]$ & 0.129 \\
\hline SOFA score & $7[4,9]$ & $8[5,10]$ & $6[4,8]$ & 0.019 \\
\hline $\mathrm{EAD}, \mathrm{n}(\%)$ & $40(34.8)$ & $25(56.8)$ & $15(21.1)$ & $<0.001$ \\
\hline PNF, n (\%) & $5(4.3)$ & $4(9.1)$ & $1(1.4)$ & 0.050 \\
\hline ICU stay (days) & $6.3[3.3,6.2]$ & $9.8[3.8,10.8]$ & $4.5[2.8,5.6]$ & 0.002 \\
\hline Hospital stay (days) & $46.2[26.9,62.8]$ & $40.7[27.3,46.7]$ & $48.7[27.2,71.2]$ & 0.234 \\
\hline Patient death 28 days, $\mathrm{n}(\%)$ & $9(7.8)$ & 7 (15.9) & $2(2.8)$ & 0.011 \\
\hline
\end{tabular}

Values were expressed as mean $\pm \mathrm{SD}$, mean $[\mathrm{IQR}]$, or $\mathrm{n}(\%) .^{\ddagger}$, the postoperative data was collected on admission to ICU immediately. AKI, acute kidney injury; WBC, white blood cell; NLR, neutrophil to lymphocyte ratio; TB, total bilirubin; DB, direct bilirubin; AST, aspartate transaminase; ALT, alanine transaminase; PT, prothrombin time; INR, international normalized ratio; PA, prothrombin activity; PRBCs, packed red blood cells; IVC, inferior vena cava; CIT, cold ischemic time; Mb, myoglobin; SOFA, Sequential Organ Failure Assessment; APACHE II, Acute Physiology Chronic Health Disease Classification System II; MAP, mean arterial pressure; PCT, procalcitonin; EAD, early allograft dysfunction; PNF, primary allograft non-function; ICU, intensive care unit; SD, standard deviation; IQR, interquartile range. 

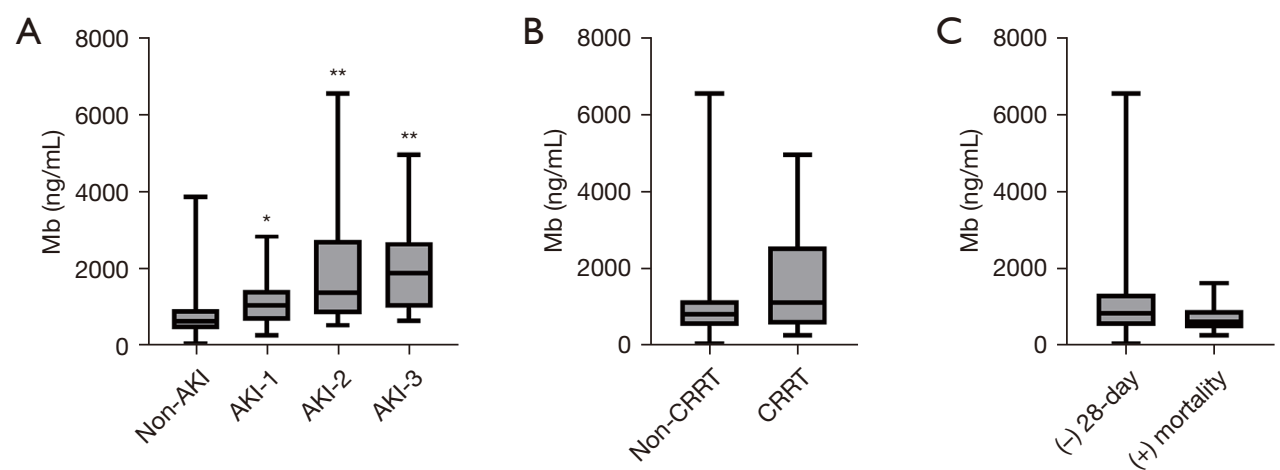

Figure 2 Distribution characteristics of $\mathrm{Mb}$ on POD0. (A) Distribution characteristics of serum Mb levels according to different AKI grade; (B) the relationship between serum $\mathrm{Mb}$ and need of CRRT; (C) analyzed the effect of serum level on 28 -day mortality. ${ }^{*} \mathrm{P}<0.05$ and ${ }^{* *} \mathrm{P}<0.01$ compared with non-AKI group. $\mathrm{Mb}$, myoglobin; POD, post-operative day; AKI, acute kidney injury; CRRT, continuous renal replacement therapy.

patients entered in ICU immediately. Obviously, there was significantly different in serum $\mathrm{Mb}$ on POD0 between AKI group and non-AKI group $\{1,531[717,1,969]$ vs. 772 $[435,940], \mathrm{P}<0.001\}$. Albumin on POD0 was statistical significant between two groups $(29.2 \pm 5.4$ vs. $31.6 \pm 4.6$, $\mathrm{P}=0.025)$. And patients with AKI were higher about AST on POD0 $\{2,737[1,059,5,515]$ vs. $1,371[606,1,586], \mathrm{P}=0.001\}$ and ALT $\{1,186[332,2,128]$ vs. $576[273,745], \mathrm{P}=0.006\}$ than those without AKI. And except ammonia, statistically significance could be discovered in PT, INR and PA (all $\mathrm{P}<0.05$ respectively). Besides, patients with and without AKI showed significant different in the value of PCT on POD0 [with higher in AKI group, 53.5 (14.6, 64.2) vs. 26.1 (5.4, 29.5), $\mathrm{P}=0.001]$. And the postoperative SOFA score was $8[5,10]$ and $6[4,8]$ for AKI group and non-AKI group $(\mathrm{P}=0.019)$. In patients with $\mathrm{AKI}$, the value of lactate after LT was higher [3.2 $(1.4,3.3)$ vs. $2.4(1.1,2.6), \mathrm{P}=0.049]$. However, these two groups did not differ with regard to preoperative WBC counts, Neutrophil-Lymphocyte ratio, hemoglobin, platelets, albumin, AST, ALT and other biochemical indicators, as well as surgery data including intraoperative blood loss, $\mathrm{PRBCs}$ transfusion, duration of IVC interruption, CIT and WIT ( $>>0.05)$.

\section{Outcomes}

There were 115 patients enrolled in this study, and 9 patients died within 28 days. Patients with AKI after LT were associated with a higher mortality [7 (15.9\%) vs. 2 (2.8\%), $\mathrm{P}=0.011]$ within 28 days and required longer periods of ICU stay $[9.8(3.8,10.8)$ vs. $4.5(2.8,5.6), \mathrm{P}=0.002]$. But the hospital stay of AKI group was higher than non-AKI group [40.7 (27.3, 46.7) vs. 49.8 (27.2, 71.2), $\mathrm{P}=0.189]$, despite the hospital stay not reaching significant statistical difference. Additionally, in our study, we found that the incidence of $\mathrm{EAD}$ was closely related to AKI. Thirty-four patients experienced $\mathrm{EAD}$, and the incidence was higher in AKI group [25 (56.8\%) vs. 15 (21.1\%), $\mathrm{P}<0.001]$. Besides, the incidence of PNF was not significantly different in these two groups, but it was not difficult to find higher occurrence in AKI group [4 (9.1) vs. 1 (1.1), $\mathrm{P}=0.050]$.

\section{Distribution characteristics of $M b$}

In our study, there were 44 patients with AKI; stage 1 $(n=22,50 \%)$, stage $2(n=15,34.1 \%)$, stage $3(n=8,18.2 \%)$ classified according to KDIGO criteria. The distribution characteristic of serum $\mathrm{Mb}$ for different stages was showed in the Figure $2 \mathrm{~A}$. Compared with non-AKI group, the serum $\mathrm{Mb}$ was higher in three stages respectively $(\mathrm{P}<0.01)$. However, there was no statistical difference between the three stages when compared with stage 1 and stage 2 or stage 2 and stage $3(\mathrm{P}>0.05)$. And we found that the serum presented its highest point on stage 3 compared with stage 1 or stage 2 . According to need for CRRT and 28-days mortality, we also compared the serum $\mathrm{Mb}$ level for different outcomes (Figure 2B,2C). There was no difference in these groups $(\mathrm{P}>0.05)$. But we found that the serum $\mathrm{Mb}$ was higher in CRRT group even if no significant difference. 
Table 3 Multivariable analysis of independent risk factor for AKI

\begin{tabular}{lccc}
\hline Variables & OR & $95 \% \mathrm{Cl}$ & P value \\
\hline Albumin $(\mathrm{g} / \mathrm{L})$ & 0.88 & $0.80-0.99$ & 0.008 \\
$\mathrm{ALT}(\mathrm{U} / \mathrm{L})$ & 1.00 & $1.00-1.01$ & 0.001 \\
$\mathrm{Mb}(\mathrm{ng} / \mathrm{mL})$ & 1.01 & $1.00-1.01$ & 0.001 \\
\hline
\end{tabular}

All the above indexes were on PODO. AKI, acute kidney injury; ALT, alanine transaminase; Mb, myoglobin; OR, odd ratio; Cl, confidence interval; POD0, post-operative day 0.

Table 4 Regression models for predicting AKI

\begin{tabular}{lcccc}
\hline Regression model & AUC & SE & $95 \% \mathrm{Cl}$ & P value \\
\hline Albumin (g/L) & 0.617 & 0.055 & $0.265-0.482$ & 0.025 \\
ALT (U/L) & 0.654 & 0.055 & $0.545-0.762$ & 0.006 \\
$\mathrm{Mb}(\mathrm{ng} / \mathrm{mL})$ & 0.755 & 0.048 & $0.661-0.849$ & $<0.001$ \\
Albumin + ALT & 0.759 & 0.047 & $0.667-0.851$ & $<0.001$ \\
Albumin + Mb & 0.770 & 0.050 & $0.673-0.867$ & $<0.001$ \\
ALT + Mb & 0.807 & 0.043 & $0.723-0.890$ & $<0.001$ \\
Albumin + ALT + Mb & 0.826 & 0.040 & $0.747-0.904$ & $<0.001$ \\
\hline
\end{tabular}

All the above indexes were on POD0. AKI, acute kidney injury; ALT, alanine transaminase; Mb, myoglobin; AUC, area under the curve; SE, standard error; $\mathrm{Cl}$, confidence interval; PODO, post-operative day 0 .

\section{Risk factors for $A K I$}

Statistical analysis was performed to evaluate the association between all variables and post-LT AKI using the univariate and multivariate regression. And results of univariate logistic regression analysis of the preoperative, intraoperative and postoperative risk factors were presented in Table S2. The result showed that duration surgery [odd ratio (OR) $=1.59, \mathrm{P}=0.023,95 \%$ CI: 1.07-2.39], intraoperative blood loss $(\mathrm{OR}=0.21, \mathrm{P}=0.023$, 95\% CI: 0.06-0.81), duration of IVC interruption (OR $=0.98, \mathrm{P}=0.034,95 \%$ CI: $0.95-$ 1.00), albumin on POD0 (OR $=0.81, \mathrm{P}=0.024,95 \% \mathrm{CI}$ : $0.67-0.97)$, ALT on POD0 (OR $=1.00, \mathrm{P}=0.007,95 \% \mathrm{CI}$ : $1.00-1.01)$ and serum $\mathrm{Mb}$ on $\mathrm{POD} 0(\mathrm{OR}=1.01, \mathrm{P}=0.006$, 95\% CI: $1.00-1.01)$ may be the risk factors for new AKI. Furthermore, we used a multivariate logistic regression model including these variables to identify whether they are independent risk factors for AKI after LT. And the result showed that serum $\mathrm{Mb}$ level on POD0 $(\mathrm{OR}=1.01$, $\mathrm{P}=0.001$, 95\% CI: $1.00-1.01$ ), albumin on POD0 (OR $=0.88, \mathrm{P}=0.008,95 \%$ CI: $0.80-0.99)$ and ALT on POD0 (OR $=1.00, \mathrm{P}=0.001,95 \% \mathrm{CI}: 1.00-1.01)$ were independent risk factors for postoperative new AKI after LT (Table 3).

\section{Predictive value of $M b$}

Finally, the AUC-ROC curve was evaluated the diagnostic performance to predict new AKI after LT, as presented in Figure 3. An AUC of 0.5 represents a test with a poor association and an invalid diagnostic capacity, whereas an AUC of 1.0 represents a test with a perfect diagnostic value (30). According to the above multivariable logistic regression analysis, we compared the prognostic value of the serum Mb values, albumin, ALT on POD0 separately and the combination of these factors. The area under the curves (AUCs) of these regression models were listed in Table 4 which revealed serum $\mathrm{Mb}$ on POD0, albumin on POD0 and ALT on POD0 were the independent risk factors for AKI after LT. In addition, the ROC curves of these three factors respectively were showed in Figure 3. The AUC of serum $\mathrm{Mb}$ on POD0 alone was 0.755 , and further, a $\mathrm{Mb}$ of $957 \mathrm{ng} / \mathrm{mL}$ was the most accurate value for predicting AKI. Furthermore, the ROC curves of the combination of these factors were compared in multivariable regression model within $\mathrm{Mb}$ (albumin $+\mathrm{ALT}+\mathrm{Mb}$ ) and without Mb (albumin + ALT) (Figure 4). The AUC of the multivariable regression model with $\mathrm{Mb}$ was 0.826 (sensitivity: $77.3 \%$, specificity: 


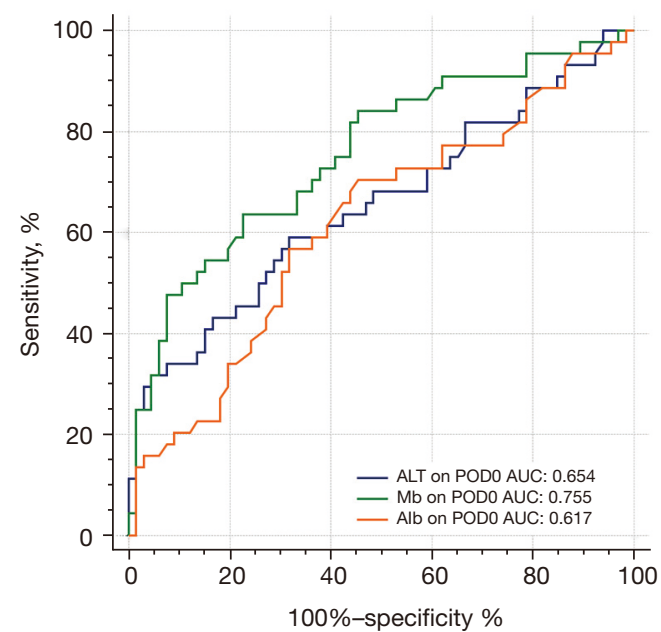

Figure 3 ROC curves for postoperative serum $\mathrm{Mb}$, albumin and ALT associated with AKI after LT. AUC of postoperative $\mathrm{Mb}=0.751$, which marked by green line; AUC of postoperative albumin $=0.722$, which marked by red line; AUC of postoperative ALT $=0.638$, which marked by blue line. A $\mathrm{Mb}$ of $957 \mathrm{ng} / \mathrm{mL}$ was the most accurate cut-off value with the highest Youden index (Youden index $=0.403$, sensitivity $=0.634$, specificity $=0.769$ ) for predicting postoperative AKI. ROC, receiver operating characteristic; Mb, myoglobin; ALT, alanine aminotransferase; AKI, acute kidney injury; LT, liver transplantation; AUC, area under the curve; Alb, albumin.

$75.8 \%, 95 \%$ CI: $0.747-0.904, \mathrm{P}<0.001)$, and 0.807 in model without Mb.

\section{Discussion}

Although LT is still considered the definitive treatment for end-stage liver disease currently, sever complications such as AKI remains a major concern (31). At present, the occurrence of severe complications, short-term and longterm mortality have not been improved fundamentally in patients due to ongoing LT. In patients underwent LT, there will be postoperative bleeding, severe infection, hepatic artery thrombosis, acute graft rejection, EAD, etc.

AKI after major surgery is a common complication which may develop CKD, even end-stage kidney disease (9). The overall estimated incidence of AKI after LT was 40.7\% (32). In our study, the incidence of AKI was $38.3 \%$ which was lower than reported previously. The reason was that our hospital is a LT center and the technology was relatively mature. Besides, adverse outcomes including increased

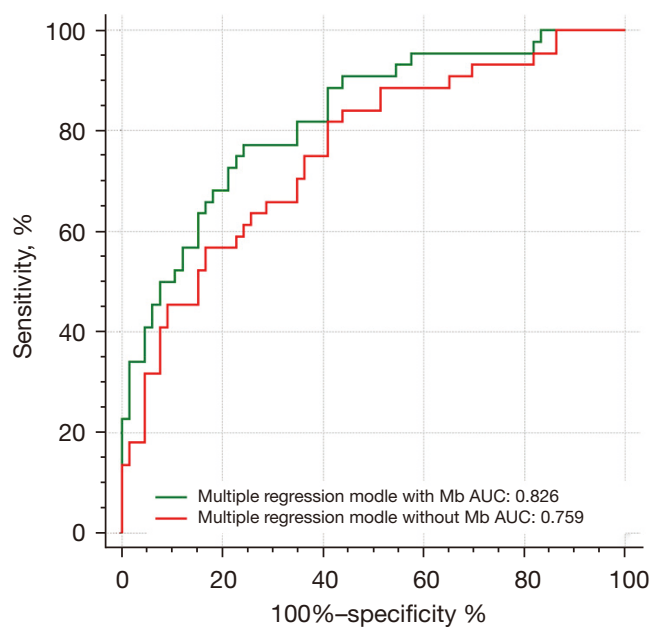

Figure 4 ROC curves for multiple regression model with or without serum $\mathrm{Mb}$ on POD0. Green line represents the model with $\mathrm{Mb}, \mathrm{AUC}=0.826$; red line represents the model without $\mathrm{Mb}, \mathrm{AUC}=0.759$. ROC, receiver operating characteristic; $\mathrm{Mb}$, myoglobin; POD0, post-operative day 0; AUC, area under the curve.

hospital duration of stays, hypertension, malnutrition and an increase of mortality may be observed in patients with AKI $(33,34)$. In our study, we found that AKI after LT was associated with longer ICU stay. Interestingly, the hospital stay of patients with AKI was longer than patients without AKI, although the hospital stay was no significantly different in our study. We considered that this may be related to the reduced survival of AKI group within 28 days after surgery. However, the aetiology of AKI after LT is complex and unclear. There are many factors that contribute to the development of AKI after LT. There have been shown that renal hypo-perfusion, surgery time and hemodynamic instability at intraoperative, systemic inflammatory response, along with the choice of antibiotics which have nephrotoxicity in the post-transplant period, were common aetiological factors $(25,33,35,36)$. Risk factors for AKI in the pre-transplant period include syndecan-1 level, the level of serum NGAL, high vitamin B12, recipient age and C-reactive protein (CRP) $(19,24,37,38)$. Although these clinical variables have provided predictive values in identifying the occurrence of AKI after LT, the additional use of specific serum biomarkers might further improve the ability to identify patients with AKI.

Our current results showed that the level of serum $\mathrm{Mb}$ in the AKI group increased significantly compared with non- 
AKI group. And the Mb level reflected the severity of illness (Figure 2). Therefore, Mb may be a predictive biomarker for AKI after LT. The reason that we selected the serum $\mathrm{Mb}$ after ICU admission immediately was for the purpose of early diagnosis for AKI. Mb is present in cardiac myocytes as well as smooth muscle cells, as an $\mathrm{O}_{2}$ storage depot (39). It will be released from the injured cells and participate in circulation when these cells are damaged, increasing the incidence of AKI. It is well known that the level of serum $\mathrm{Mb}$ will increase in patients with rhabdomyolysis (40). And a previous study showed that higher serum $\mathrm{Mb}$ could be detected in the early stage of sepsis (18). More recently, it has been shown that $\mathrm{Mb}$ could serve as an early predictor of AKI (41). However, there is still lack of studies on the prognostic value of $\mathrm{Mb}$ in surgical patients. Expect that hyper-Mb has been ascribed as a sign of successful arterial embolectomy (42). During transplantation especially after anhepatic phase, ischemia-reperfusion injury will occur in patients, leading to insufficient blood supply or microcirculatory disturbance in muscle cells, and resulting in varying degrees of muscle cells injury. Postoperative hyper-dynamic blood circulation can cause an increase of ventricular tension and pressure, leading to cardiomyocyte apoptosis (43). In agreement with our study, Fricke et al. retrospectively analyzed patients due to extremely ischemiareperfusion damage which showed that the serum $\mathrm{Mb}$ level permitted a prognosis about the extent of the expected impairment after revascularization (44). And they described the limit of $20,000 \mu \mathrm{g} / \mathrm{L} \mathrm{Mb}$ as the critical level for the occurrence of organ failure. They indicated that intraoperatively quick reperfusion maybe decrease the release of $\mathrm{Mb}$. To our knowledge, our current study was the first to demonstrate an association between postoperative serum $\mathrm{Mb}$ level and new AKI in the setting of LT.

In addition, we found that neither MELD score nor MELD-Na score were significantly different between AKI group and non-AKI group in present study which was not consistent with a previous study $(45,46)$. The reason why higher MELD score had no association with the risk of AKI may be its including indicators such as TB, serum creatinine and INR. However, hepatic encephalopathy and ascites are also important indicators for evaluating the severity of disease. And it places a considerable importance on the value of creatinine in MELD score, but we excluded patients with preoperative renal dysfunction. Hence, MELD score was not related to the occurrence of AKI.

We found obvious differences in duration surgery, the mean of intraoperative urine output and the maximum dose of norepinephrine. These findings were consistent with previous studies $(47,48)$. These indicators could result from hemodynamic instability and hypovolemia during surgery, hence, resulting in postoperative AKI. It had been reported that intraoperative oliguria was related to postoperative AKI after major abdominal surgery (49).

Our present findings also documented the significant difference in AST and ALT on POD0 in patients with and without AKI. But in multivariable regression analysis, the level of AST was not the independent risk factor of AKI. Since AST is also present in cardiac and skeletal muscle, so the level of ALT plays a critical role as a probe for acute and chronic liver injuries (50). And liver dysfunction can lead to hemodynamic instability, sever infection, and sequentially the occurrence of AKI. So it can explain our result that the level of postoperative ALT was closely related to AKI. And this can also be used to explain the differences in IB, PT, INR and PA which reflecting the recovery of liver function. In our study, serum PCT levels after surgery were significantly higher in patients with AKI than those without AKI $(\mathrm{P}=0.001)$. But the PCT levels were not an independent risk factor for AKI which confirmed by multivariable logistic regression. This result is similar with previous study which demonstrated that PCT was insufficient to provide diagnostic use (51). Besides, our study found that AKI was associated with higher lactate that represents poorer tissue perfusion than non-AKI group. But the lactate level was also not an effective predictive factor for AKI.

Through logistic regression analysis, postoperative serum $\mathrm{Mb}$, albumin and ALT after admission were the independent risk factors for new AKI. Sang et al. retrospectively studied 1,440 patients after LT divided into two groups, including patients whose postoperative albumin level was less than $3.0 \mathrm{~g} / \mathrm{dL}$ and greater than $3.0 \mathrm{~g} / \mathrm{dL}$. They indicated that early postoperative hypoalbuminemia within 2 days was an independent risk factor for AKI (20). Similarly, in our study, there was a significant difference in albumin between two groups and it was also found as an independent risk factor for AKI. Hypoalbuminemia maybe result from inflammation, infection and sepsis (52). Besides, hypoalbuminemia can result in depletion of effective intravascular volume. But the influence of albumin on renal function is still not clear. Maybe albumin can improve renal blood flow autoregulation (53).

$\mathrm{Mb}$ has the special function related to oxygen transport and storage. As a result, the serum $\mathrm{Mb}$ may reflect the energy metabolism of organs such as renal $(54,55)$. The ROC curves confirmed that serum Mb level could be 
used as a biomarker for predicting the occurrence of AKI after LT. And what we discovered was the joint prediction including Mb, albumin and LT had a much better effect. Moreover, our study found that higher serum $\mathrm{Mb}$ will be more requires for CRRT (Figure 2). Therefore, serum $\mathrm{Mb}$ level may be an ideal biomarker for predicting the risk of CRRT. New experiments may be needed to verify this view. Of course, many factors did influence the occurrence of AKI and we studied only serum parameters. So we measured our data which are the most pathological value after admission immediately.

At present, the main treatments for AKI after LT were prevention of early rejection, control of infection, fluid replacement and CRRT (56). Although the effectiveness of these treatments is still controversial, our result may offer new opportunities to identify patients at risk within a time window that enables early treatment.

Our study is innovative because there are few literatures that focus on LT patients to research the relationship between $\mathrm{Mb}$ and AKI. But our study has several limitations. First, it was a single-center analysis. Although the data were electronically collected, a slight deviation was possible and some important data could be missing. Second, our sample size was small due to some missing data, so further studies will be needed. Third, we did not examine other biomarkers such as NGAL, Kim-1, Cystatin C, etc. So we have no ability to determine the accuracy of $\mathrm{Mb}$ for predicting the risk of AKI. Finally, as our study was conducted in a single center and department, it lacked sufficient donor-related indicators.

\section{Conclusions}

In patients after LT, serum $\mathrm{Mb}$ is correlated with new AKI, and it is an independent risk factor for AKI. Through introducing postoperative $\mathrm{Mb}$, the accuracy of predicting model for AKI was increased. Besides, higher level of serum $\mathrm{Mb}$ was related to higher AKI stage. Also, Mb was found to be association with need for CRRT. These findings need to be confirmed by larger prospective clinical trials.

\section{Acknowledgments}

Funding: This work was supported, in part, by grants from the National Natural Science Foundation (No. 81372042), the Scientific and Breeding Program of Beijing Municipal Hospitals (No. PX2019010) and Beijing Municipal Science \& Technology Commission (No. Z191100006619032).

\section{Footnote}

Reporting Checklist: The authors have completed the STARD reporting checklist (available at https://dx.doi.org/10.21037/ apm-21-2340).

Data Sharing Statement: Available at https://dx.doi. org/10.21037/apm-21-2340

Peer Review File: Available at https://dx.doi.org/10.21037/ apm-21-2340

Conflicts of Interest: All authors have completed the ICMJE uniform disclosure form (available at https://dx.doi. org/10.21037/apm-21-2340). The authors have no conflicts of interest to declare.

Ethical Statement: The authors are accountable for all aspects of the work in ensuring that questions related to the accuracy or integrity of any part of the work are appropriately investigated and resolved. The study conformed to the provisions of the Declaration of Helsinki (as revised in 2013). The protocol was reviewed and approved by the institutional review committee of Beijing Chaoyang Hospital (approval number: 2021-55) and informed consent was taken from all individual participants.

Open Access Statement: This is an Open Access article distributed in accordance with the Creative Commons Attribution-NonCommercial-NoDerivs 4.0 International License (CC BY-NC-ND 4.0), which permits the noncommercial replication and distribution of the article with the strict proviso that no changes or edits are made and the original work is properly cited (including links to both the formal publication through the relevant DOI and the license). See: https://creativecommons.org/licenses/by-nc-nd/4.0/.

\section{References}

1. Kim WR, Lake JR, Smith JM, et al. OPTN/SRTR 2016 annual data report: liver. Am J Transplant 2018;18 Suppl 1:172-253.

2. Neuberger J. An update on liver transplantation: a critical review. J Autoimmun 2016;66:51-9.

3. Thomson AW, Vionnet J, Sanchez-Fueyo A. Understanding, predicting and achieving liver transplant tolerance: from bench to bedside. Nat Rev Gastroenterol Hepatol 2020;17:719-39. 
4. Weidhase L, de Fallois J, Haußig E, et al. Myoglobin clearance with continuous veno-venous hemodialysis using high cutoff dialyzer versus continuous veno-venous hemodiafiltration using high-flux dialyzer: a prospective randomized controlled trial. Crit Care 2020;24:644.

5. Carrier FM, Chassé M, Sylvestre MP, et al. Effects of intraoperative fluid balance during liver transplantation on postoperative acute kidney injury: an observational cohort study. Transplantation 2020;104:1419-28.

6. Utsumi M, Umeda Y, Sadamori H, et al. Risk factors for acute renal injury in living donor liver transplantation: evaluation of the RIFLE criteria. Transpl Int 2013;26:842-52.

7. Wyatt CM, Arons RR. The burden of acute renal failure in nonrenal solid organ transplantation. Transplantation 2004;78:1351-5.

8. Cantaluppi V, Quercia AD, Dellepiane S, et al. Interaction between systemic inflammation and renal tubular epithelial cells. Nephrol Dial Transplant 2014;29:2004-11.

9. Barri YM, Sanchez EQ, Jennings LW, et al. Acute kidney injury following liver transplantation: definition and outcome. Liver Transpl 2009;15:475-83.

10. Dennen P, Douglas IS, Anderson R. Acute kidney injury in the intensive care unit: an update and primer for the intensivist. Crit Care Med 2010;38:261-75.

11. de Geus HR, Betjes MG, Bakker J. Biomarkers for the prediction of acute kidney injury: a narrative review on current status and future challenges. Clin Kidney J 2012;5:102-8.

12. Kim H, Hur M, Cruz DN, et al. Plasma neutrophil gelatinase-associated lipocalin as a biomarker for acute kidney injury in critically ill patients with suspected sepsis. Clin Biochem 2013;46:1414-8.

13. Burns KE, Chu MW, Novick RJ, et al. Perioperative $\mathrm{N}$-acetylcysteine to prevent renal dysfunction in high-risk patients undergoing cabg surgery: a randomized controlled trial. JAMA 2005;294:342-50.

14. Laurence AS. Serum myoglobin and creatine kinase following surgery. Br J Anaesth 2000;84:763-6.

15. Sorrentino SA, Kielstein JT, Lukasz A, et al. High permeability dialysis membrane allows effective removal of myoglobin in acute kidney injury resulting from rhabdomyolysis. Crit Care Med 2011;39:184-6.

16. Kurt-Mangold M, Drees D, Krasowski MD. Extremely high myoglobin plasma concentrations producing hook effect in a critically ill patient. Clin Chim Acta 2012;414:179-81.

17. Shumyantseva VV, Bulko TV, Sigolaeva LV, et al. Polymer matrices with molecular memory as affine adsorbents for the determination of myoglobin as a cardiac marker of acute myocardial infarction by voltammetry. Journal of Analytical Chemistry 2017;72:410-4.

18. Yao L, Liu Z, Zhu J, et al. Higher serum level of myoglobin could predict more severity and poor outcome for patients with sepsis. Am J Emerg Med 2016;34:948-52.

19. Park J, Choi JH, Choi HJ, et al. Predictive role of vitamin B12 in acute kidney injury in living donor liver transplantation: a propensity score matching analysis. BMJ Open 2020;10:e038990.

20. Sang BH, Bang JY, Song JG, et al. Hypoalbuminemia within two postoperative days is an independent risk factor for acute kidney injury following living donor liver transplantation: a propensity score analysis of 998 consecutive patients. Crit Care Med 2015;43:2552-61.

21. Kim WH, Oh HW, Yang SM, et al. Intraoperative hemodynamic parameters and acute kidney injury after living donor liver transplantation. Transplantation 2019;103:1877-86.

22. Jia HM, Zheng Y, Huang LF, et al. Derivation and validation of plasma endostatin for predicting renal recovery from acute kidney injury: a prospective validation study. Crit Care 2018;22:305.

23. Jochmans I, Meurisse N, Neyrinck A, et al. Hepatic ischemia/reperfusion injury associates with acute kidney injury in liver transplantation: Prospective cohort study. Liver Transpl 2017;23:634-44.

24. Cezar LC, Meneses GC, da Silva Junior GB, et al. Intraoperative systemic biomarkers predict post-liver transplantation acute kidney injury. Eur J Gastroenterol Hepatol 2021;33:1556-63.

25. Gameiro J, Fonseca JA, Neves M, et al. Acute kidney injury in major abdominal surgery: incidence, risk factors, pathogenesis and outcomes. Ann Intensive Care 2018;8:22

26. Ostermann M, Joannidis M. Acute kidney injury 2016: diagnosis and diagnostic workup. Crit Care 2016;20:299.

27. De Rosa S, Samoni S, Ronco C. Creatinine-based definitions: from baseline creatinine to serum creatinine adjustment in intensive care. Crit Care 2016;20:69.

28. Tandukar S, Palevsky PM. Continuous renal replacement therapy: who, when, why, and how. Chest 2019;155:626-38.

29. Olthoff KM, Kulik L, Samstein B, et al. Validation of a current definition of early allograft dysfunction in liver transplant recipients and analysis of risk factors. Liver Transpl 2010;16:943-9.

30. Hoo ZH, Candlish J, Teare D. What is an ROC curve? Emerg Med J 2017;34:357-9. 
31. Hilmi IA, Damian D, Al-Khafaji A, et al. Acute kidney injury following orthotopic liver transplantation: incidence, risk factors, and effects on patient and graft outcomes. Br J Anaesth 2015;114:919-26.

32. Klaus F, Keitel da Silva C, Meinerz G, et al. Acute kidney injury after liver transplantation: incidence and mortality. Transplant Proc 2014;46:1819-21.

33. Thongprayoon C, Kaewput W, Thamcharoen N, et al. Incidence and impact of acute kidney injury after liver transplantation: a meta-analysis. J Clin Med 2019;8:372.

34. Barreto AG, Daher EF, Silva Junior GB, et al. Risk factors for acute kidney injury and 30-day mortality after liver transplantation. Ann Hepatol 2015;14:688-94.

35. Bell S, Ross VC, Zealley KA, et al. Management of postoperative acute kidney injury. QJM 2017;110:695-700.

36. Grams ME, Sang Y, Coresh J, et al. Acute kidney injury after major surgery: a retrospective analysis of veterans health administration data. Am J Kidney Dis 2016;67:872-80.

37. Tan L, Yang Y, Ma G, et al. Early acute kidney injury after liver transplantation in patients with normal preoperative renal function. Clin Res Hepatol Gastroenterol 2019;43:475-82.

38. Tang Y, Huang XR, Lv J, et al. C-reactive protein promotes acute kidney injury by impairing G1/ S-dependent tubular epithelium cell regeneration. Clin Sci (Lond) 2014;126:645-59.

39. Hendgen-Cotta UB, Kelm M, Rassaf T. Myoglobin functions in the heart. Free Radic Biol Med 2014;73:252-9.

40. Huerta-Alardín AL, Varon J, Marik PE. Bench-to-bedside review: Rhabdomyolysis -- an overview for clinicians. Crit Care 2005;9:158-69.

41. Premru V, Kovač J, Ponikvar R. Use of myoglobin as a marker and predictor in myoglobinuric acute kidney injury. Ther Apher Dial 2013;17:391-5.

42. Andersen PT, Møller-Petersen J, Henneberg EW, et al. Hypermyoglobinemia after successful arterial embolectomy. Surgery 1987;102:25-31.

43. Carrier FM, Chassé M, Wang HT, et al. Restrictive fluid management strategies and outcomes in liver transplantation: a systematic review. Can J Anaesth 2020;67:109-27.

44. Fricke P, Weiß G, Lippert H. Ischämie-/ReperfusionsSyndrom-Das Serummyoglobin im Verlauf und seine Wertigkeit als Prognoseparameter Eine retrospektive Analyse klinischer Daten. Intensivmedizin und Notfallmedizin 2002;39:38-46.
45. Chen $W$, Zheng R, Baade PD, et al. Cancer statistics in China, 2015. CA Cancer J Clin 2016;66:115-32.

46. Karapanagiotou A, Kydona C, Dimitriadis C, et al. Acute kidney injury after orthotopic liver transplantation. Transplant Proc 2012;44:2727-9.

47. Smoter P, Nyckowski P, Grat M, et al. Risk factors of acute renal failure after orthotopic liver transplantation: singlecenter experience. Transplant Proc 2014;46:2786-9.

48. Sirivatanauksorn Y, Parakonthun T, Premasathian N, et al. Renal dysfunction after orthotopic liver transplantation. Transplant Proc 2014;46:818-21.

49. Mizota T, Yamamoto Y, Hamada M, et al. Intraoperative oliguria predicts acute kidney injury after major abdominal surgery. Br J Anaesth 2017;119:1127-34.

50. Dufour DR, Lott JA, Nolte FS, et al. Diagnosis and monitoring of hepatic injury. I. Performance characteristics of laboratory tests. Clin Chem 2000;46:2027-49.

51. Chun K, Chung W, Kim AJ, et al. Association between acute kidney injury and serum procalcitonin levels and their diagnostic usefulness in critically ill patients. Sci Rep 2019;9:4777.

52. Sun HY, Singh N, Cacciarelli TV, et al. Dysregulated expression of T-helper cell responses and susceptibility to infections in high-risk liver transplant recipients. Transpl Immunol 2008;20:68-72.

53. Garcia-Martinez R, Noiret L, Sen S, et al. Albumin infusion improves renal blood flow autoregulation in patients with acute decompensation of cirrhosis and acute kidney injury. Liver Int 2015;35:335-43.

54. Ljungman C, Eriksson I, Ronquist G, et al. Muscle ATP and lactate and the release of myoglobin and carbanhydrase III in acute lower-limb ischaemia. Eur J Vasc Surg 1991;5:407-14.

55. Tilakaratne HK, Hunter SK, Rodgers VG. Mathematical modeling of myoglobin facilitated transport of oxygen in devices containing myoglobin-expressing cells. Math Biosci 2002;176:253-67.

56. Ronco C, Bellomo R, Kellum JA. Acute kidney injury. Lancet 2019;394:1949-64.

Cite this article as: Han YZ, Zhang J, Gao RY, Zhao S, Zheng Y, Ding Q, Xin X, Yu K, Huang LF, Li WX. Predictive utility of postoperative serum myoglobin in acute kidney injury after liver transplantation. Ann Palliat Med 2021;10(11):1126511277. doi: 10.21037/apm-21-2340 
Supplementary

Table S1 KDIGO criteria of AKI for adult patients

\begin{tabular}{lll}
\hline Stage & Serum creatinine & Urine output \\
\hline 1 & $1.5-1.9$ times baseline; or $\geq 0.3 \mathrm{mg} / \mathrm{dL}(\geq 26.5 \mu \mathrm{mol} / \mathrm{L})$ increase & $<0.5 \mathrm{~mL} / \mathrm{kg} / \mathrm{h} \mathrm{for} 6-12 \mathrm{hours}$ \\
2 & $2.0-2.9$ times baseline & $<0.5 \mathrm{~mL} / \mathrm{kg} / \mathrm{h} \mathrm{for} \geq 12 \mathrm{hours}$ \\
3 & $\begin{array}{l}3.0 \text { times baseline; or increase in serum creatinine to } \geq 4.0 \mathrm{mg} / \mathrm{dL}(353.6 \mu \mathrm{mol} / \mathrm{L}) ; \text { or initiation of renal } \\
\text { replacement therapy; or in patients }<18 \text { years, decrease in eGFR to } 35 \mathrm{~mL} / \mathrm{min} \text { per } 1.73 \mathrm{~mL} / \mathrm{kg} / \mathrm{h} \mathrm{for} \geq 24 \mathrm{hours;}\end{array}$ & or anuria for $\geq 12$ hours \\
\hline
\end{tabular}

KDIGO, Kidney Disease Improving Global Outcome; AKI, acute kidney injury.

Table S2 Univariable regression analysis comparing baseline clinical characteristics

\begin{tabular}{|c|c|c|c|}
\hline Variables & OR & $95 \% \mathrm{Cl}$ & $P$ value \\
\hline \multicolumn{4}{|l|}{ Preoperative parameters } \\
\hline Male gender & 0.80 & $0.15-4.46$ & 0.804 \\
\hline BMI $\left(\mathrm{kg} / \mathrm{m}^{2}\right)$ & 1.09 & $0.92-1.31$ & 0.316 \\
\hline MELD score & 1.13 & $0.96-1.34$ & 0.149 \\
\hline MELD-Na score & 0.89 & $0.74-1.07$ & 0.220 \\
\hline \multicolumn{4}{|l|}{ Intraoperative parameters } \\
\hline Duration surgery (hours) & 1.59 & $1.07-2.39$ & 0.023 \\
\hline Blood loss (L) & 0.22 & $0.06-0.81$ & 0.023 \\
\hline Intraoperative urine output (mL/h) & 0.99 & $0.99-1.00$ & 0.413 \\
\hline Duration of IVC interruption (min) & 0.98 & $0.95-1.00$ & 0.034 \\
\hline Maximum dose of norepinephrine $(\mu \mathrm{g} / \mathrm{kg} / \mathrm{min})$ & 0.64 & $0.04-10.25$ & 0.756 \\
\hline SOFA score & 0.98 & $0.80-1.21$ & 0.881 \\
\hline APACHE II score & 0.99 & $0.89-1.12$ & 0.916 \\
\hline \multicolumn{4}{|l|}{ Postoperative parameters } \\
\hline Lactate (mmol/L) & 1.07 & $0.84-1.36$ & 0.604 \\
\hline Albumin $(g / L)$ & 0.81 & $0.67-0.97$ & 0.024 \\
\hline AST (U/L) & 1.00 & $0.99-1.00$ & 0.253 \\
\hline ALT (U/L) & 1.00 & $1.00-1.01$ & 0.007 \\
\hline РСТ (ng/mL) & 1.00 & $0.99-1.02$ & 0.773 \\
\hline PT (s) & 1.42 & $0.87-2.32$ & 0.164 \\
\hline INR & 0.34 & $0.01-29.11$ & 0.633 \\
\hline PA (\%) & 1.07 & $0.92-1.26$ & 0.369 \\
\hline $\mathrm{Mb}(\mathrm{ng} / \mathrm{mL})$ & 1.01 & $1.00-1.01$ & 0.006 \\
\hline
\end{tabular}

Postoperative parameters were PODO. BMI, body mass index; MELD, model for end-stage liver disease; IVC, inferior vena cava; SOFA, Sequential Organ Failure Assessment; APACHE II, Acute Physiology Chronic Health Disease Classification System II; AST, aspartate transaminase; ALT, alanine transaminase; PCT, procalcitonin; PT, prothrombin time; INR, international normalized ratio; PA, prothrombin activity; Mb, myoglobin; OR, odd ratio; $\mathrm{Cl}$, confidence interval; PODO, post-operative day 0. 